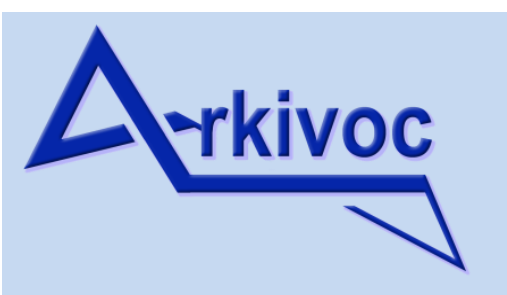

Free to Authors and Readers

\section{A Platinum Open Access Journal} for Organic Chemistry

DOAJ Seal
Paper

Arkivoc 2022, part iv, 0-0

to be inserted by editorial office

\title{
A modified synthesis of (Z)-pyrethrolone
}

\section{Todd E. Markham, ${ }^{a, b, c}$ Peter J. Duggan, ${ }^{a, c}$ and Martin R. Johnston*a,b}

${ }^{a}$ College of Science and Engineering, Flinders University, Adelaide, South Australia 5042, Australia ${ }^{b}$ Flinders Institute for Nanoscale Science and Technology, Flinders University, Adelaide, South Australia 5042, Australia

${ }^{c}$ CSIRO Manufacturing, Research Way, Clayton, Victoria 3168, Australia

Email: martin.johnston@flinders.edu.au

Received 11-16-2021

Accepted Manuscript 01-28-2022

Published on line 02-03-2022

\section{Abstract}

An accessible, efficient, and reliable synthesis for the production of (Z)-pyrethrolone remains necessary as previous syntheses suffer from drawbacks including the use of toxic reagents, expensive starting materials and lack of regioselectivity in the production of key intermediates. This work attempts to alleviate the issues of prior syntheses by making use of well-known and regioselective transformations for the efficient synthesis of (Z)-pyrethrolone. Ultimately, (Z)-pyrethrolone is generated in an overall $20 \%$ yield over five steps from a cheap, easily accessible starting material using reliable, optimised transformations.

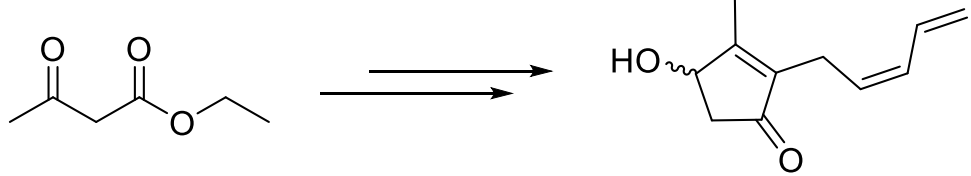

Cheap, non-toxic, accessible starting material

Regioselective transformations

5 steps, $20 \%$ overall yield

Keywords: Pyrethrolone, natural product, regioselective synthesis 


\section{Introduction}

Pyrethrins 1-3 (Figure 1) are a class of insecticidally active esters that are commercially extracted from the pyrethrum daisy, Tanacetum cinerariifolium, in the form of pyrethrum extract. This extract has been utilised in domestic and agricultural pest control products with an extensive history as a pest control agent. The popularity of pyrethrum insecticides is due to their lack of environmental persistence, broad spectrum activity and the limited development of insecticidally resistant species. ${ }^{1,2}$ Many of these favourable qualities stem from the propensity of the pyrethrins 1-3 to degrade under typical environmental conditions however, such degradation can lead to loss of the insecticidal activity on long-term storage.

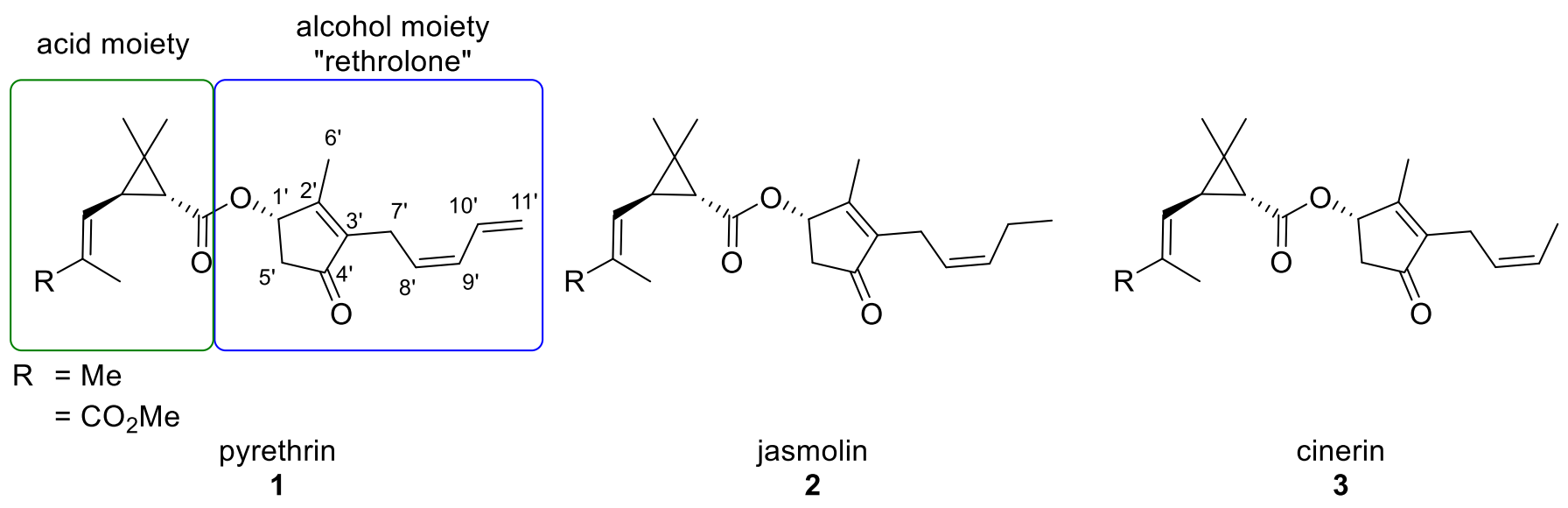

Figure 1. The six natural pyrethrins 1-3 comprising the pyrethrum extract of $T$. cinerariifolium. The main components of the pyrethrin scaffold and key atomic numbering of the rethrolone are highlighted.

Pyrethrins 1 are the major components in the extract and particularly susceptible to degradation, especially by oxidative means. ${ }^{3}$ The labile nature of pyrethrins 1 under typical environmental conditions can partially be attributed to the high content of reactive functionalities found in the rethrolone portion of the molecule (Figure 1), namely (Z)-pyrethrolone $9^{3,4}$ Due to the high content of these reactive functionalities in (Z)-pyrethrolone 9, its efficient and accessible synthesis may serve as a means to explore the degradative properties of this rethrolone moiety in more depth and further explore the structure-activity relationships of the pyrethrins 1 more extensively through synthetic modification. While a number of pre-existing syntheses have been published in the literature since the elucidation of the rethrolone structure, many are lengthy or make use of undesirable, toxic reagents. The most recent of these syntheses uses prallethrin alcohol $\mathbf{7}$ as a starting material, ${ }^{5}$ however this is difficult to obtain, expensive and unavailable in appreciable quantities. Alternatively, the most recent synthesis starting from easily accessible starting materials was reported by Matsuo and co-workers generating (Z)-pyrethrolone $\mathbf{9}$ over five synthetic operations. Notably, an intermediate chiral resolution was undertaken to afford the natural $\left(S\right.$ )-enantiomer (Scheme 1). ${ }^{6,7}$ However, this pathway suffers from the drawback of relying on regioselective reaction with intermediates containing multiple sites of reactivity, specifically the alkylation of dimethyl-3-oxoglutarate (4) and the subsequent decarboxylative aldol addition, giving the critical linear intermediate 6 . 

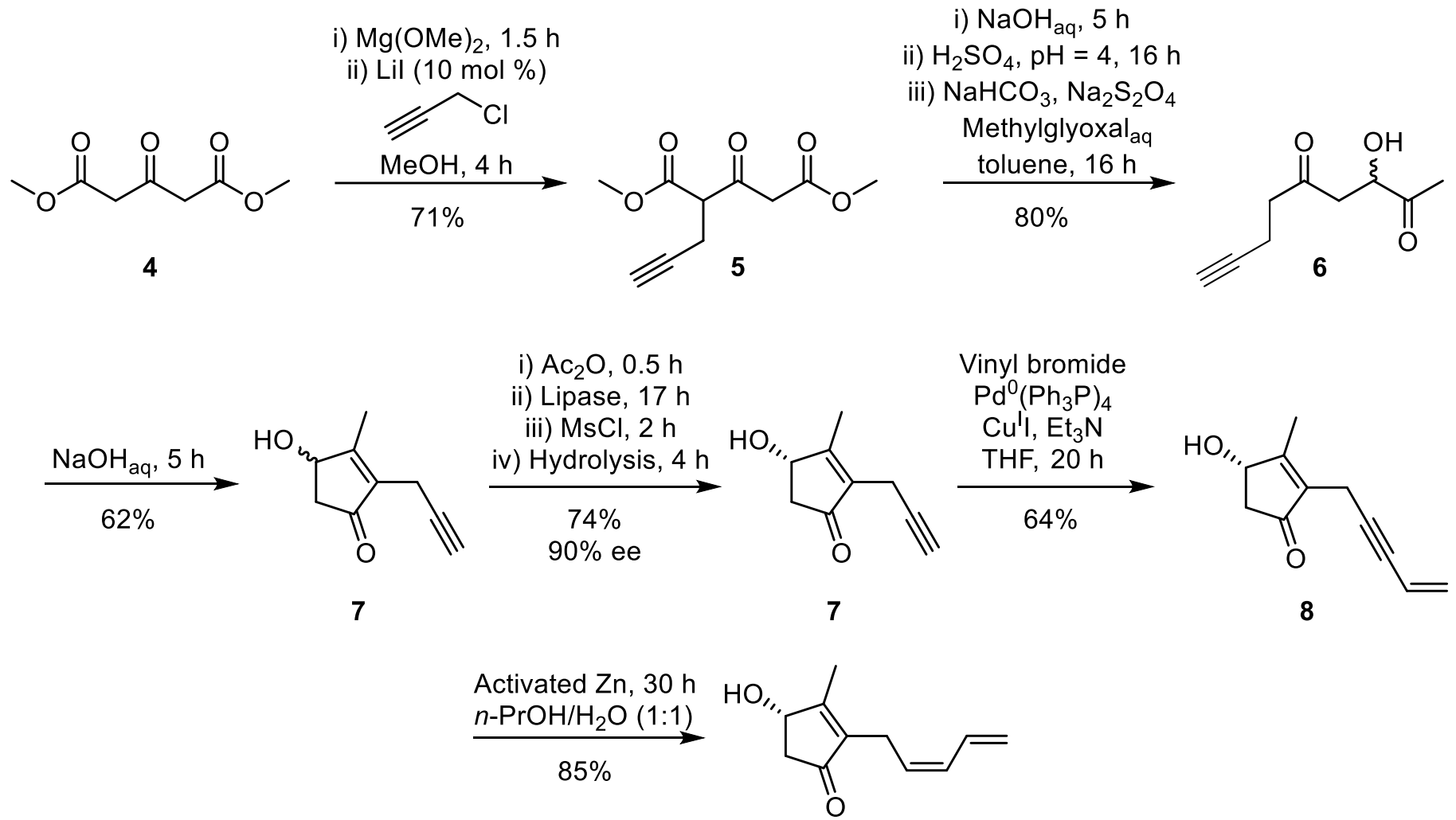

9

Scheme 1. Matsuo's synthesis of (Z)-pyrethrolone 9 with enzymatic chiral resolution to afford the natural (S)configuration.

Herein, we recount the complications encountered on attempting to repeat the synthesis detailed by Matsuo's group and the resulting modifications that have resulted in a reliable synthesis of (Z)-pyrethrolone $\mathbf{9}$.

\section{Results and Discussion}

Initially, attempts at the synthesis of (Z)-pyrethrolone 9 employed the described methodology by Matsuo and co-workers using the cheap and accessible dimethyl 3-oxoglutarate (4) as starting material. As briefly highlighted above, this pathway starts with the monoalkylation of dimethyl 3-oxoglutarate (4) via its magnesium enolate with propynyl chloride. Notably, the attempts described here used propargyl bromide instead of propargyl chloride due to its significantly lower cost and availability in greater quantities making it preferential for scalable synthesis of the desired pyrethrolone target 9 (Scheme 2). Generally, multiple alkylation events were observed in the employed protocol utilising freshly prepared magnesium methoxide as the base. Despite attempts to remedy this, either through alteration of the number of equivalents of base or by substitution of the base for sodium hydride, sodium methoxide or even potassium carbonate, multialkylated products were always present in the isolated material. Subsequent attempts at purification by conventional distillation under vacuum required temperatures exceeding $150{ }^{\circ} \mathrm{C}$ and failed to yield the purified monoalkylated oxoglutarate 5. Instead, exposure to these high temperatures gave a resinous material likely obtained by the decomposition by-products derived from several oxoglutarate species. In addition, attempts to purify the mixture by column chromatography failed, despite the use of a range of eluents, due to 
co-elution of the monoalkylated product 5 with its higher alkylated counterparts. Fortunately, short path distillation by Kugelrohr minimised the decomposition of the material however, with the distillate being a mixture containing residual starting material albeit enriched with the desired monoalkylated product $\mathbf{5}$. After exhaustive attempts to isolate this monoalkylated oxoglutarate $\mathbf{5}$, the enriched mixture was subjected to the subsequent decarboxylative aldol addition procedure.

Generating the key linear intermediate 6 from the oxoglutarate 5 proceeds via a one-pot ester hydrolysisdecarboxylation-aldol addition. Notably, this process requires a regioselective decarboxylative-aldol addition to the unsubstituted side of the oxoglutarate while limiting the alkylated side to only the decarboxylation. The presence of the propargyl unit was proposed by Matsuo and co-workers to allow for rapid decarboxylation of the neighbouring carboxylate ultimately giving the desired regioselectivity for the subsequent aldol addition. As previously highlighted by Matsuo's group, this regioselectivity was attributed to the greater electron withdrawing capabilities of the propargyl unit in comparison to a previously implemented allyl derivative that exhibited no regioselectivity. ${ }^{6}$ However, application of the enriched alkylated oxoglutarate mixture to the described method yielded a complex mixture of products, some associated with the presence of the oxoglutarate starting material 4 and some from a lack of regioselectivity in the decarboxylation process. Specifically, the oxoglutarate starting material 4 can participate in the same reactivity sequence to give the unalkylated counterpart $\mathbf{1 1}$ to the desired product $\mathbf{6}$ as well as products stemming from incomplete hydrolysis, decarboxylation and alternate aldol reactivities (Scheme 2). More importantly, the monoalkylated oxoglutarate $\mathbf{5}$ can also be susceptible to the processes described for the starting material giving a series of byproducts. In particular, the most prominent by-products originating from the alkylated oxoglutarate 5 were 5 hexyn-2-one 10, resulting from rapid decarboxylation of both carboxylate sites, and the alternate regioisomer 12 where aldol addition has occurred on the substituted side of the alkylated oxoglutarate 5. Unfortunately, attempts to purify the mixture isolated from this decarboxylative aldol protocol were unsuccessful due to the abundance and structural similarity of by-products formed from both the propargyl $\mathbf{5}$ and unsubstituted $\mathbf{4}$ oxoglutarates. While milder conditions may have counteracted the formation of the undesired decarboxylation by-products, the regioselectivity of the subsequent aldol addition remained a concern. In addition, continuation of the pathway would quickly become unfeasible with the build-up of impurities that could not be removed at each successive step. As such, alternate protocols that could produce pivotal intermediates in the pathway were investigated.

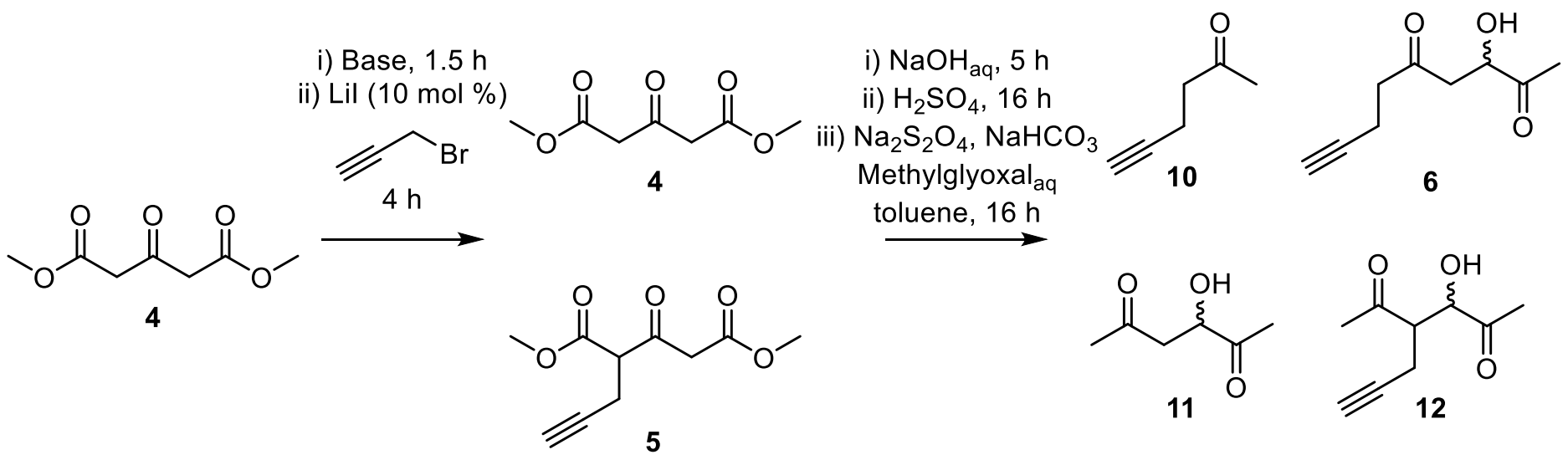

Scheme 2. Attempted synthesis of (Z)-pyrethrolone 9 resulting in compounding impurities due to a lack of regioselectivity. 
As described above, the alkylation of dimethyl 3-oxoglutarate (4) by Matsuo and co-workers is required to give the monoalkylated product $\mathbf{5}$ despite potential for multi-alkylation at the same or alternate enolisable sites. The subsequent decarboxylative aldol reaction relies on a regioselective decarboxylative aldol addition to occur on the unsubstituted portion of $\mathbf{5}$ whilst limiting the substituted side to solely the decarboxylation process. This heavy dependence on regioselectivity in the presence of multiple points of reactivity and the various complications described above prompted retrosynthetic analysis (Scheme 3 ) in pursuit of a more efficient and selective approach to the key intermediate 6.
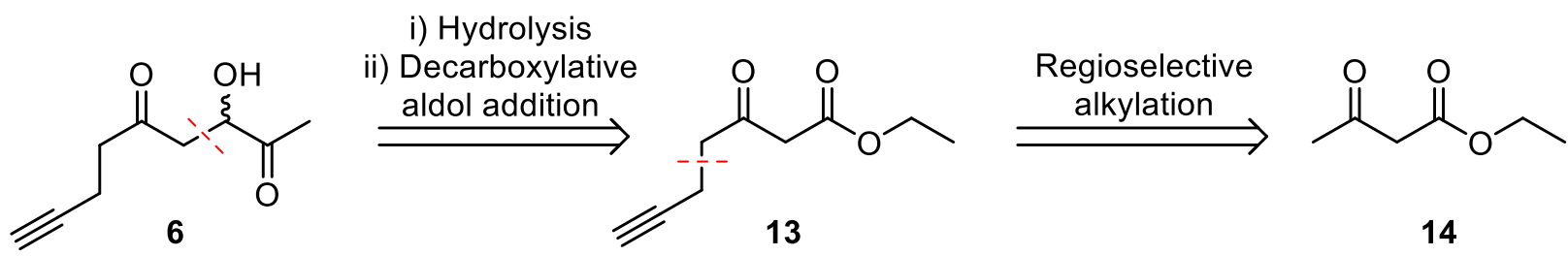

Scheme 3. Retrosynthesis for an efficient, regioselective synthesis of 6.

From this retrosynthesis it was clear that ethyl acetoacetate (14) had potential as a replacement for the dimethyl 3-oxoglutarate (4) from Matsuo's work. Specifically, ethyl acetoacetate (14) can be selectively monoalkylated at the terminal enolisable carbon by well-known dianion chemistry giving an intermediate 13 with only a single carboxylate site available for the decarboxylative aldol process, allowing for regioselective production of the key intermediate $\mathbf{6}$. In addition, ethyl acetoacetate (14) retains all the qualities of dimethyl 3-oxoglutarate (4) as an ideal starting material, namely its low toxicity, availability in large quantities and low cost.

Ethyl 3-oxohept-6-ynoate (13) was readily prepared via the mixed metal dianion of ethyl acetoacetate. Initial treatment of ethyl acetoacetate (14) with sodium hydride gave the 1,3-dicarbonyl enolate and subsequent treatment with $n$-BuLi generated the terminal lithium enolate. Alkylation with propargyl bromide and purification by short-path distillation readily gave the desired ethyl 3-oxohept-6-ynoate (13) in a good 76\% yield (Scheme 4). This alternate intermediate was then amenable to a modified version of the decarboxylative aldol process described by Matsuo and co-workers with regioselective control now possible with only a single site of reactivity.

The original conditions described by Matsuo and co-workers made use of concentrated sulfuric acid for the decarboxylation process likely causing the rapid loss of both carboxylates in the alkylated oxoglutarate $\mathbf{5}$ resulting in the undesirable alkyne by-product $\mathbf{1 0}$. This process was modified in a bid to allow for a more controlled loss of the carboxylate and an increased opportunity for the aldol addition to take place. Notably, the use of sodium dithionite is retained due to it being implicated in preventing the formation of a catechol by-product generated by consecutive aldol events. ${ }^{8}$ As such, the ethyl ester was hydrolysed as described by Matsuo and co-workers by slow addition of the ethyl 3-oxohept-6-ynoate (13) to a cooled aqueous solution of sodium hydroxide. Following a $5 \mathrm{~h}$ reaction time, the $\mathrm{pH}$ of the mixture was adjusted to approximately 5 with dilute hydrochloric acid. Sodium dithionite and toluene were added immediately following $\mathrm{pH}$ adjustment and an aqueous solution of methylglyoxal was added dropwise. Following overnight reaction and removal of the small amounts of the alkyne by-product $\mathbf{1 0}$ by short-path distillation, the critical intermediate $\mathbf{6}$ was generated in $66 \%$ yield (Scheme 4). With this linear acyloin 6 in hand, the cyclic rethrolone scaffold could be prepared by intramolecular aldol condensation. 


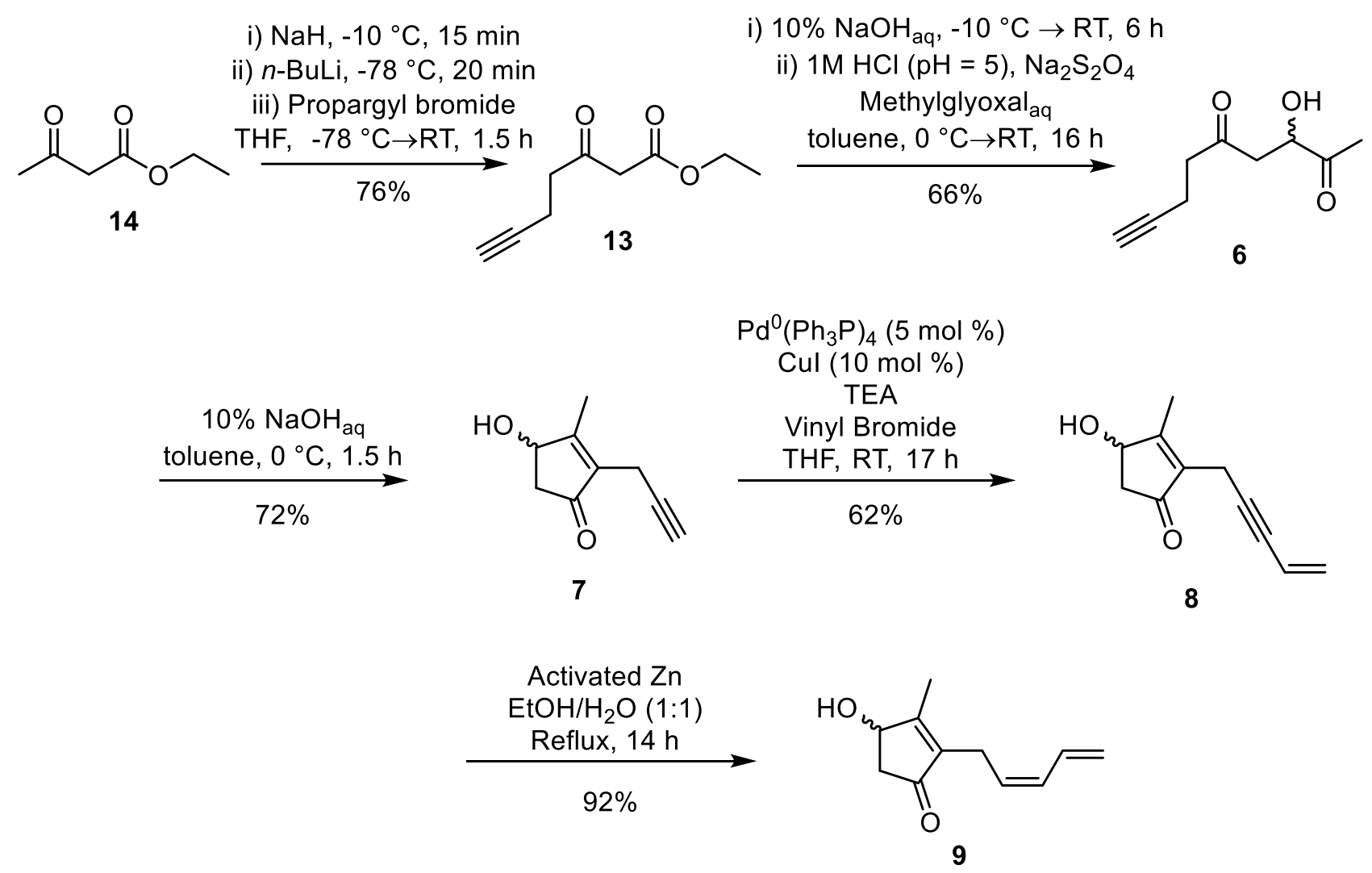

Scheme 4. A modified, regioselective synthesis for the production of (Z)-pyrethrolone 9.

Synthesis of the rethrolone scaffold has been relatively universal in the syntheses of pyrethrolone 9 to date, making use of the intramolecular aldol condensation of 1,4-diketones. ${ }^{6,9-11}$ As such, the original procedure by Matsuo and co-workers was initially used for this essential step of the pathway. Diketone $\mathbf{6}$ was added dropwise to a cooled, biphasic mixture of aqueous sodium hydroxide and toluene, and left to stir for 5 h. Following work-up, the crude mixture was shown to contain the desired rethrolone product $\mathbf{7}$ however, significant quantities of rethrolone dimers (16 and 17) were also present (Scheme 5) as indicated by the presence of alkene proton resonances and additional signals attributable to multiple propargyl side chains in the ${ }^{1} \mathrm{H}$ NMR analysis. It has been demonstrated that extended exposure of the pyrethrins 1 to basic conditions results in the formation of a cyclopentadienone due to an elimination reaction in the rethrolone, that rapidly undergoes Diels-Alder cycloadditions to afford rethrolone dimers. ${ }^{4}$ By extension, the rethrolone $\mathbf{7}$ can likely react in an analogous process to generate the cyclopentadienone 15. This cyclopentadienone $\mathbf{1 5}$ is expected to rapidly dimerise in one of two orientations by Diels-Alder cycloaddition giving the dimers $\mathbf{1 6}$ and $\mathbf{1 7}$ (Scheme $5)$. 


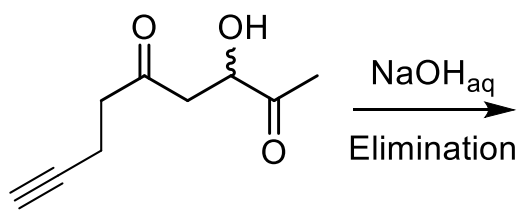

6

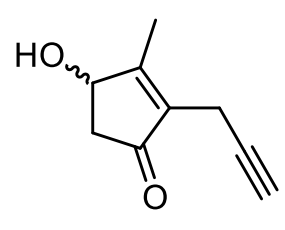

7

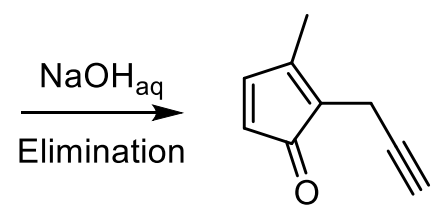

15
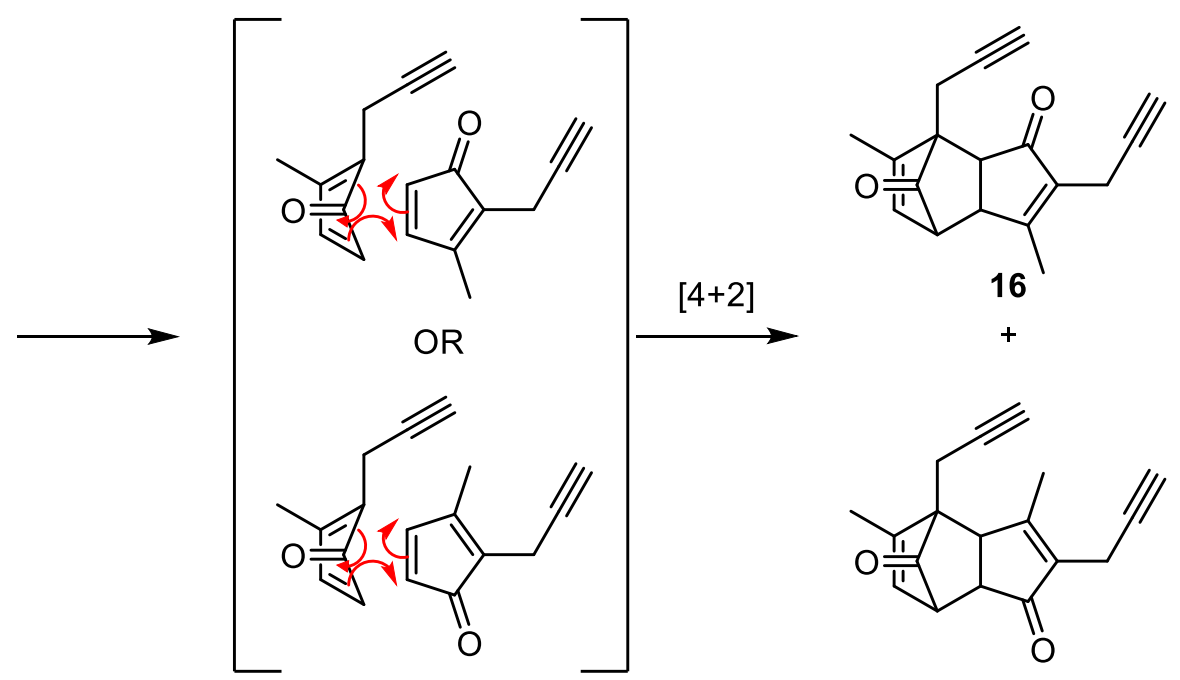

17

Scheme 5. Elimination-Diels-Alder cycloaddition cascade resulting in rethrolone dimers 16 and 17 under alkali conditions.

Optimisation of the 1,4-diketone intramolecular aldol condensation allowed for reaction times to be shortened to $1.5 \mathrm{~h}$, minimising exposure of the newly formed rethrolone 7 to the alkali conditions and therefore, limiting the formation of the dimers 16 and $\mathbf{1 7}$ without compromising yield. Ultimately, the rethrolone 7 could be isolated, following purification by short-path distillation, in a respectable $72 \%$ yield (Scheme 4).

Production of the final carbon scaffold could be readily achieved by implementing similar Sonogashira cross-coupling conditions to those used by Matsuo and co-workers. ${ }^{5,7}$ Prior to addition of the catalytic components, a solution of vinyl bromide in THF was deaereated with argon to prevent the competitive Glaser coupling of the alkynyl substrate 7. The enyne 8 was generated by reaction with the vinyl bromide in the presence of $\mathrm{Pd}\left(\mathrm{Ph}_{3} \mathrm{P}\right)_{4}, \mathrm{Cul}$ and $\mathrm{Et}_{3} \mathrm{~N}$. The crude reaction mixture could then be readily purified by a short, silica gel plug to give the desired enyne 8 in a $62 \%$ yield (Scheme 4 ).

The final step in the synthetic pathway was a selective, partial reduction of the alkyne in the rethrolone side chain to the corresponding cis-alkene. The original method described by Matsuo and co-workers was implemented where the enyne $\mathbf{8}$ was added to a suspension of activated zinc in aqueous $n$-propanol. This mixture was then heated under reflux for $30 \mathrm{~h}$ under inert atmosphere before the isolation of a crude mixture which contained over-reduced materials rather than the desired (Z)-pyrethrolone 9. More recently, a shorter reaction time and alternate solvent mixture have been described. ${ }^{5}$ Notably, these reactions require the use of over 150 equivalents of activated zinc which may contribute to the observed over-reduction and generate significant quantities of heavy metal waste. Optimisation of this protocol allowed for a significant drop in the amount of zinc used from the aforementioned 150 to 20 equivalents. As such, a solution of the enyne 8 in ethanol was introduced to an aqueous suspension of activated zinc under inert atmosphere. Following heating 
of this mixture under reflux for $14 \mathrm{~h},(Z)$-pyrethrolone 9 was isolated without the need for purification in an excellent $92 \%$ yield (Scheme 4). (Z)-Pyrethrolone 9 was readily identified by NMR analysis with the spectroscopic data in agreement with previously reported data. ${ }^{5,7}$ Specifically, the H-8' (5.33 ppm) and H-9' (6.01 ppm) proton resonances of the newly formed double bond acted as diagnostic signals for the identification of (Z)-pyrethrolone 9 with their correlations to $\mathrm{H}-\mathbf{7}^{\prime}$ and $\mathrm{H}-10^{\prime}$, respectively, serving to confirm the regiochemistry of the side chain. Additionally, the $J_{H-H}$ between these two double bond resonances being of comparable magnitude to typical cisoid coupling constants confirmed the desired $(Z)$-configuration was achieved.

Overall, (Z)-pyrethrolone 9 was generated in a yield of $20 \%$ in five synthetic operations using reliable, regioselective transformations (Scheme 4).

\section{Conclusions}

(Z)-Pyrethrolone 9 was synthesised over a series of five accessible and reliable synthetic operations in an overall $20 \%$ yield. Notably, this pathway makes use of an easily accessed, cheap and non-toxic starting material in the form of ethyl acetoacetate (14). Additionally, this starting material overcomes the regioselectivity challenges associated with the original pathway described by Matsuo and co-workers. Finally, the pathway does not require tedious column chromatography-based purifications and has potential for generality in the production of other rethrolones.

\section{Experimental Section}

General. Reagents and solvents were purchased from commercial sources and used without further purification unless otherwise stated. THF was dried by distillation over sodium-benzophenone ketal. Zinc was activated prior to use with concentrated (32\%) hydrochloric acid, washed with water, ethanol, acetone and diethyl ether before being dried under vacuum.

${ }^{1} \mathrm{H}$ and ${ }^{13} \mathrm{C}$ NMR spectra were recorded on a Bruker $600 \mathrm{MHz}$ Avance III NMR spectrometer at 600 and 150 $\mathrm{MHz}$, respectively. All spectra were obtained at $298 \mathrm{~K}$ using $\mathrm{CDCl}_{3}$ as solvent and internal lock. All spectra were referenced to the residual solvent signal $\left(\mathrm{CDCl}_{3}:{ }^{1} \mathrm{H} 7.26 \mathrm{ppm},{ }^{13} \mathrm{C} 77.0 \mathrm{ppm}\right)$ and are reported as follows: (1) chemical shift (ppm); (2) integration; (3) multiplicity [s, singlet; $d$, doublet; $t$, triplet; q, quartet; dd, doublet of doublets; dt, doublet of triplets; ddd, doublet of doublet of doublets; m, multiplet; brs, broad singlet; *, multiplicity assigned based on a series of homonuclear decoupling experiments (Supporting Information)]; (4) coupling constant $(\mathrm{Hz})$. Signals were assigned with the aid of 2D homonuclear $\left({ }^{1} \mathrm{H}-{ }^{1} \mathrm{H}\right)$ correlation spectroscopy (COSY) and heteronuclear $\left({ }^{1} \mathrm{H}-{ }^{13} \mathrm{C}\right)$ correlation spectroscopy (HSQC, HMBC) (Supporting Information).

Fourier-transform infrared spectroscopy was undertaken on a PerkinElmer Spectrum100 spectrometer with an attenuated total reflectance (ATR) diamond crystal attachment. All spectra are reported in wavenumbers $(\bar{v}$, $\mathrm{cm}^{-1}$ ).

High-resolution mass spectrometry (HRMS) was performed on a PerkinElmer AxION Direct Sample Analysis (DSA) with an $\mathrm{AxION}^{\circledR} 2$ time of flight (ToF) mass spectrometer using atmospheric pressure chemical ionisation (APCI) in positive ion mode. 
Ethyl 3-oxohept-6-ynoate (13). ${ }^{12,13}$ Ethyl acetoacetate (14) $(5.0 \mathrm{~g}, 38 \mathrm{mmol})$ was slowly added to a suspension of $60 \%$ wt in mineral oil sodium hydride $(2.1 \mathrm{~g}, 52 \mathrm{mmol})$ in dry THF $(30 \mathrm{~mL})$ at $-15^{\circ} \mathrm{C}$ under an atmosphere of $\mathrm{N}_{2}$. After $15 \mathrm{~min}, 2.5 \mathrm{M}$ in hexanes $n$-butyl lithium $\left(16 \mathrm{~mL}, 40 \mathrm{mmol}\right.$ ) was slowly added at $-78{ }^{\circ} \mathrm{C}$ and the mixture was left to stir for an additional $20 \mathrm{~min} .80 \% \mathrm{wt}$ in toluene propargyl bromide $(4.6 \mathrm{~mL}, 41.4 \mathrm{mmol}) \mathrm{was}$ slowly added to the mixture with continued cooling and over $1.5 \mathrm{~h}$ the reaction mixture was allowed to warm to room temperature. The reaction was quenched with saturated ammonium chloride solution $(20 \mathrm{~mL})$, acidified with $1 \mathrm{M}$ hydrochloric acid and extracted with ethyl acetate. The ethyl acetate was washed with saturated sodium chloride solution. The organic fraction was dried $\left(\mathrm{Na}_{2} \mathrm{SO}_{4}\right)$ and the solvent removed in vacuo yielding a dark brown liquid. The mixture was distilled by Kugelrohr short path distillation yielding 12 as a colourless liquid $\left(110{ }^{\circ} \mathrm{C}\right.$ at $\left.0.8 \mathrm{mmHg}\right)(4.98 \mathrm{~g}, 76 \%) .{ }^{1} \mathrm{H} \mathrm{NMR}\left(600 \mathrm{MHz}, \mathrm{CDCl}_{3}\right) \delta 4.20(2 \mathrm{H}, \mathrm{q}, J 7.1 \mathrm{~Hz}), 3.46$ $(2 \mathrm{H}, \mathrm{s}), 2.81(2 \mathrm{H}, \mathrm{t}, J 7.4 \mathrm{~Hz}), 2.47(2 \mathrm{H}, \mathrm{td}, J 7.4,2.6 \mathrm{~Hz}), 1.95(1 \mathrm{H}, \mathrm{t}, J 2.6 \mathrm{~Hz}), 1.27(3 \mathrm{H}, \mathrm{t}, J 7.1 \mathrm{~Hz}) ;{ }^{13} \mathrm{C} \mathrm{NMR}$ $\left(150 \mathrm{MHz}_{\mathrm{CDCl}}\right) \delta 200.7,167.0,82.6,69.1,61.6,49.4,41.7,14.2,13.0$. FTIR $(\bar{v}): 3287,2984,2934,2120$, $1739,1715,1410,1367,1316,1190,1083,1031,641$. HRMS calculated for $\mathrm{C}_{9} \mathrm{H}_{13} \mathrm{O}_{3}[\mathrm{M}+\mathrm{H}]^{+}:$169.0859, observed: 169.0854 .

3-Hydroxy-8-nonyne-2,5-dione (6). ${ }^{6}$ Ethyl 3-oxohept-6-ynoate (12) (4.25 g, $25.3 \mathrm{mmol}$ ) was slowly added to a solution of $10 \%$ wt sodium hydroxide $(15 \mathrm{~mL})$ cooled over an ice bath. The reaction mixture was left for $6 \mathrm{~h}$ at room temperature before being cooled to $0{ }^{\circ} \mathrm{C}$ and acidified to $\mathrm{pH} 5$ with $1 \mathrm{M}$ hydrochloric acid. With continued cooling, sodium dithionite $(0.9 \mathrm{~g}, 5.2 \mathrm{mmol})$ and toluene $(15 \mathrm{~mL})$ were added followed by the slow addition of $40 \%$ wt in water methylglyoxal $(6.0 \mathrm{~g}, 33 \mathrm{mmol})$. After complete addition of the methylglyoxal solution, the mixture was allowed to warm to room temperature and was left to slowly stir overnight. The aqueous layer was saturated with sodium chloride and the toluene layer collected. The aqueous layer was extracted with ethyl acetate and the organic fractions combined. The combined organic extract was dried $\left(\mathrm{Na}_{2} \mathrm{SO}_{4}\right)$ and the solvent removed in vacuo yielding a dark brown, viscous oil. Short path distillation by Kugelrohr under vacuum was used to remove the undesired by-product $10\left(100{ }^{\circ} \mathrm{C}\right.$ at $\left.0.8 \mathrm{mmHg}\right)$ leaving 6 a viscous orange liquid $(2.5 \mathrm{~g}, 66 \%)$ which was used without further purification. ${ }^{1} \mathrm{H} \mathrm{NMR}\left(600 \mathrm{MHz}^{\mathrm{C}} \mathrm{CDCl}_{3}\right) \delta$ $4.36(1 \mathrm{H}, \mathrm{dd}, J 6.4,3.8 \mathrm{~Hz}), 2.97(1 \mathrm{H}, \mathrm{dd}, J 16.9,3.8 \mathrm{~Hz}), 2.84(1 \mathrm{H}, \mathrm{dd}, J 16.9,6.4 \mathrm{~Hz}), 2.73(2 \mathrm{H}, \mathrm{t}, J 7.1 \mathrm{~Hz}), 2.45$ $(2 \mathrm{H}, \mathrm{td}, J 7.1,2.6 \mathrm{~Hz}), 2.26(3 \mathrm{H}, \mathrm{s}), 1.95(1 \mathrm{H}, \mathrm{t}, J 2.6 \mathrm{~Hz}) ;{ }^{13} \mathrm{C} \mathrm{NMR}\left(150 \mathrm{MHz}, \mathrm{CDCl}_{3}\right) \delta 209.1,207.0,82.7,73.8$, 69.1, 45.5, 42.4, 25.5, 12.9. FTIR ( $\bar{v}): 3440,3285,2924,2118,1709,1631,1360,1093,639$. HRMS calculated for $\mathrm{C}_{9} \mathrm{H}_{12} \mathrm{O}_{3}[\mathrm{M}+\mathrm{H}]^{+}:$: 169.0859, observed: 169.0856 .

4-Hydroxy-3-methyl-2-(2-propyn-1-yl)-2-cyclopenten-1-one (7). ${ }^{6}$ 3-Hydroxy-8-nonyne-2,5-dione (6) (2.3 g, 14 mmol) was slowly added to a $10 \%$ wt sodium hydroxide solution $(15 \mathrm{~mL})$ and toluene $(10 \mathrm{~mL})$ over an ice-salt bath. The mixture was left to stir with continued cooling for $1.5 \mathrm{~h}$ before being acidified with concentrated (32\%) hydrochloric acid. The mixture was extracted with ethyl acetate and dried $\left(\mathrm{Na}_{2} \mathrm{SO}_{4}\right)$. The solvent was removed in vacuo and the resulting viscous liquid was distilled under vacuum $\left(150{ }^{\circ} \mathrm{C}\right.$ at $\left.0.8 \mathrm{mmHg}\right)$ giving 7 as a yellow oil (1.47 g, 72\%). ${ }^{1} \mathrm{H}$ NMR $\left(600 \mathrm{MHz}, \mathrm{CDCl}_{3}\right) \delta 4.74(1 \mathrm{H}, \mathrm{brd}, \mathrm{J} 6.1 \mathrm{~Hz}), 3.08-3.15(2 \mathrm{H}, \mathrm{m}), 2.80(1 \mathrm{H}, \mathrm{dd}, J$ 18.4, $6.1 \mathrm{~Hz}), 2.30(1 \mathrm{H}, \mathrm{dd}, J 18.4,1.9 \mathrm{~Hz}), 2.22(3 \mathrm{H}, \mathrm{s}), 1.96(1 \mathrm{H}, \mathrm{t}, J 2.7 \mathrm{~Hz}) ;{ }^{13} \mathrm{C} \mathrm{NMR}\left(150 \mathrm{MHz}, \mathrm{CDCl}_{3}\right) \delta 203.5$, 170.8, 136.7, 79.8, 71.8, 69.0, 44.1, 14.0, 12.5. FTIR ( $\bar{v}):$ 3398, 3287, 2120, 1693, 1649, 1382, 1277, 1190, 1050, 1011, 943. HRMS calculated for $\mathrm{C}_{9} \mathrm{H}_{11} \mathrm{O}_{2}[\mathrm{M}+\mathrm{H}]^{+}: 151.0754$, observed: 151.0751 .

4-Hydroxy-3-methyl-2-(4-penten-2-yn-1-yl)- 2-cyclopenten-1-one (8). ${ }^{7}$ A solution of 4-hydroxy-3-methyl-2-(2propyn-1-yl)-2-cyclopenten-1-one (7) $(741 \mathrm{mg}, 4.94 \mathrm{mmol})$ and triethylamine $(2.5 \mathrm{~mL}, 18 \mathrm{mmol})$ in $1.0 \mathrm{M}$ in THF vinyl bromide solution ( $12 \mathrm{~mL}, 12 \mathrm{mmol}$ ) was deaereated with argon over $40 \mathrm{~min}$. Under an atmosphere of argon, tetrakis(triphenylphosphine)palladium(0) (252 mg, $0.218 \mathrm{mmol}, 5 \mathrm{~mol} \%$ ) and copper(I) iodide (94 $\mathrm{mg}, 0.49 \mathrm{mmol}, 10 \mathrm{~mol} \%)$ were added with stirring. The resulting mixture was left to stir at room temperature over $17 \mathrm{~h}$. The mixture was poured over cooled $1 \mathrm{M}$ hydrochloric acid and extracted with ethyl acetate. The 
ethyl acetate solution was dried $\left(\mathrm{Na}_{2} \mathrm{SO}_{4}\right)$ and solvent removed in vacuo yielding a viscous, brown oil. The mixture was purified by a silica gel plug [DCM then DCM/EtOAc (50:50) then EtOAc] yielding 8 as an amber oil (537 mg, 62\%). ${ }^{1} \mathrm{H}$ NMR (600 MHz, $\left.\mathrm{CDCl}_{3}\right) \delta 5.73(1 \mathrm{H}, \mathrm{ddt}, J 17.5,11.1,2.2 \mathrm{~Hz}), 5.55(1 \mathrm{H}, \mathrm{dd}, J 17.5,2.2 \mathrm{~Hz})$, $5.39(1 \mathrm{H}, \mathrm{dd}, J 11.1,2.2 \mathrm{~Hz}), 4.75(1 \mathrm{H}, \mathrm{brd}, J 6.2 \mathrm{~Hz}), 3.21-3.28(2 \mathrm{H}, \mathrm{m}), 2.82(1 \mathrm{H}, \mathrm{dd}, J 18.4,6.2 \mathrm{~Hz}), 2.30(1 \mathrm{H}$, dd, J 18.4, $2.0 \mathrm{~Hz}$ ), $2.22(3 \mathrm{H}, \mathrm{s}) ;{ }^{13} \mathrm{C} \mathrm{NMR}\left(150 \mathrm{MHz}, \mathrm{CDCl}_{3}\right) \delta 203.4,170.3,137.2,126.5,117.3,86.1,79.8,71.9$, 44.2, 14.0, 13.4. FTIR (v) : 3406, 2920, 1701, 1651, 1382, 1052. HRMS calculated for $\mathrm{C}_{11} \mathrm{H}_{13} \mathrm{O}_{2}[\mathrm{M}+\mathrm{H}]^{+}$: 177.0910, observed: 177.0910 .

(Z)-Pyrethrolone (9). ${ }^{9}$ A solution of $8(200 \mathrm{mg}, 1.14 \mathrm{mmol})$ in ethanol $(5 \mathrm{~mL})$ was added to a suspension of activated zinc $(1.5 \mathrm{~g}, 23 \mathrm{mmol})$ in water $(5 \mathrm{~mL})$ under an atmosphere of nitrogen. The mixture was then heated under reflux for $14 \mathrm{~h}$ maintaining a nitrogen atmosphere. The resulting mixture was cooled to room temperature, diluted with ethyl acetate and filtered over Celite. The filtrate was washed with $2 \mathrm{M}$ hydrochloric acid and the organic fraction dried $\left(\mathrm{Na}_{2} \mathrm{SO}_{4}\right)$. The solvent was removed in vacuo yielding $(Z)$-pyrethrolone 9 (186 mg, 92\%). ${ }^{1} \mathrm{H}$ NMR (600 MHz, $\left.\mathrm{CDCl}_{3}\right) \delta 6.75\left(1 \mathrm{H}, \mathrm{ddd}^{*}, J\right.$ 16.8, 10.1, $\left.10.7 \mathrm{~Hz}\right), 6.01\left(1 \mathrm{H}, \mathrm{dd}^{*}, J 10.1,10.7\right.$ $\mathrm{Hz}), 5.33(1 \mathrm{H}, \mathrm{dt}, J 10.1,8.0 \mathrm{~Hz}), 5.22(1 \mathrm{H}, \mathrm{d}, J 16.8 \mathrm{~Hz}), 5.16(1 \mathrm{H}, \mathrm{d}, J 10.1 \mathrm{~Hz}), 4.71(1 \mathrm{H}, \mathrm{d}, J 6.2 \mathrm{~Hz}), 3.09(2 \mathrm{H}$, d, J $8.0 \mathrm{~Hz}), 2.78(1 \mathrm{H}, \mathrm{dd}, J$ 18.4, $6.2 \mathrm{~Hz}), 2.26(1 \mathrm{H}, \mathrm{d}, J 18.4 \mathrm{~Hz}), 2.08(3 \mathrm{H}, \mathrm{s}) ;{ }^{13} \mathrm{C} \mathrm{NMR}\left(150 \mathrm{MHz}, \mathrm{CDCl}_{3}\right) \delta 204.4$, 168.7, 140.3, 131.6, 130.2, 127.2, 118.2, 71.7, 44.3, 21.7, 13.7. FTIR (v) : 3397, 2971, 2903, 1690, 1646, 1433, 1382, 1313, 1256, 1190, 1051, 1010, 907. HRMS calculated for $\mathrm{C}_{11} \mathrm{H}_{14} \mathrm{O}_{2}[\mathrm{M}+\mathrm{H}]^{+}: 179.1067$, observed: 179.1060 .

\section{Acknowledgements}

This work was supported by co-investment from the CSIRO and Botanical Resources Australia. The authors acknowledge Flinders Analytical for access to and insight into the use of the Perkin Elmer DSA-ToF mass spectrometer. T. E. M thanks Flinders University for the provision of a Flinders University Research Scholarship.

\section{Supplementary Material}

Spectroscopic characterisation data for compounds 6-9 and 13 are collated in the supporting information.

\section{References}

1. 1. Bullivant, M. J.; Pattenden, G. Pestic. Sci. 1976, 7, 231-235.

https://doi.org/10.1002/ps.2780070304

2. Elliott, M. Pestic. Sci. 1989, 27, 337-351.

https://doi.org/10.1002/ps.2780270403

3. Freemont, J. A.; Littler, S. W.; Hutt, O. E.; Mauger, S.; Meyer, A. G.; Winkler, D. A.; Kerr, M. G.; Ryan, J. H.; Cole, H. F.; Duggan, P. J. J. Agric. Food Chem. 2016, 64, 7134-7141.

https://doi.org/10.1021/acs.jafc.6b02959 
4. Hutt, O. E.; Freemont, J. A.; Littler, S.; Duggan, P. J.; Tsanaktsidis, J.; Cole, H.; Kerr, M.; Ryan, J. H. Acta Hortic. 2015, 1073, 181-190.

https://doi.org/10.17660/ActaHortic.2015.1073.25

5. Kawamoto, M.; Moriyama, M.; Ashida, Y.; Matsuo, N.; Tanabe, Y. J. Org. Chem. 2020, 85, 2984-2999. https://doi.org/10.1021/acs.joc.9b02767

6. Matsuo, N.; Fujita, F.; Magara, O.; Yamazaki, H.; Aketa, K.; Nishioka, T.; Itaya, N. Agric. Biol. Chem. 1982, 46, 1911-1912.

https://doi.org/10.1271/bbb1961.46.1911

7. Matsuo, N.; Takagaki, T.; Watanabe, K.; Ohno, N. Biosci., Biotechnol., Biochem. 1993, 57, 693-694. https://doi.org/10.1271/bbb.57.693

8. Kato, T.; Mochizuki, M.; Okano, S.; Matsuo, N. Synth. Commun. 2003, 33, 3977-3982. https://doi.org/10.1081/SCC-120026323

9. Crombie, L.; Hemesley, P.; Pattenden, G. J. Chem. Soc. 1969, 1016-1024. https://doi.org/10.1039/j39690001016

10. Crombie, L.; Harper, S. H.; Newman, F. C. J. Chem. Soc. 1956, 1956, 3963-3971. https://doi.org/10.1039/jr9560003963

11. Tsuji, J.; Yamakawa, T.; Mandai, T. Tetrahedron Lett. 1979, 39, 3741-3744. https://doi.org/10.1016/S0040-4039(01)95513-3

12. Weiler, L. J. Am. Chem. Soc. 1970, 92, 6702-6704. https://doi.org/10.1021/ja00725a088

13. Hayakawa, K.; Yodo, M.; Ohsuki, S.; Kanematsu, K. J. Am. Chem. Soc. 1984, 106, 6735-6740. https://doi.org/10.1021/ja00334a044 